\title{
Eutrophication: Can nanophosphorous control this menace?
}

Deepika Bhalla, Siddhartha S. Mukhopadhyay ${ }^{1}$

Department of Soils, Punjab Agricultural University, Ludhiana - 141004, India [1 e-mail siddhartha_soil@yahoo.co.in] 
Every night earth is between you and the sun 
We are gifted with this...... Dream of a poet 


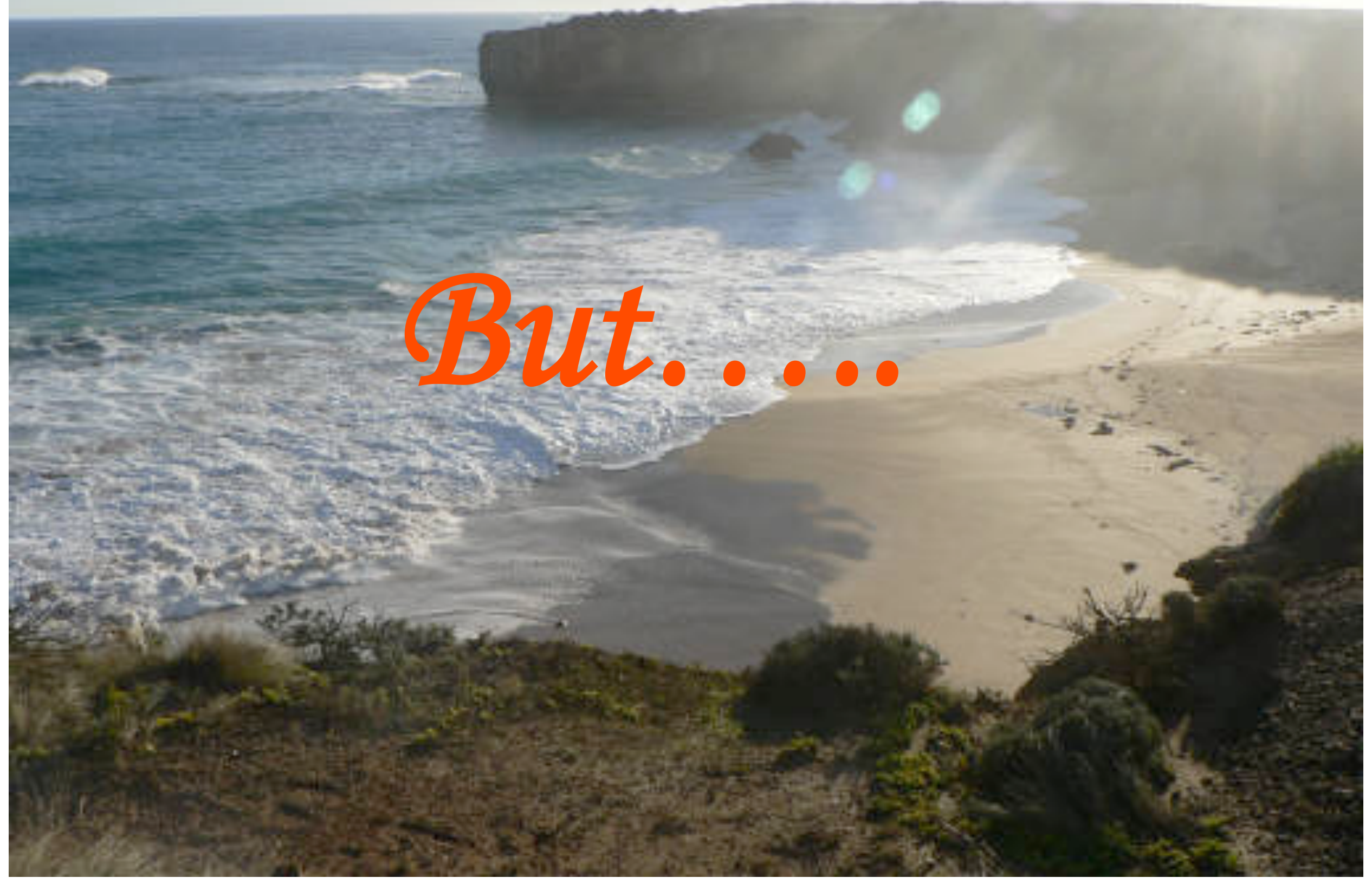




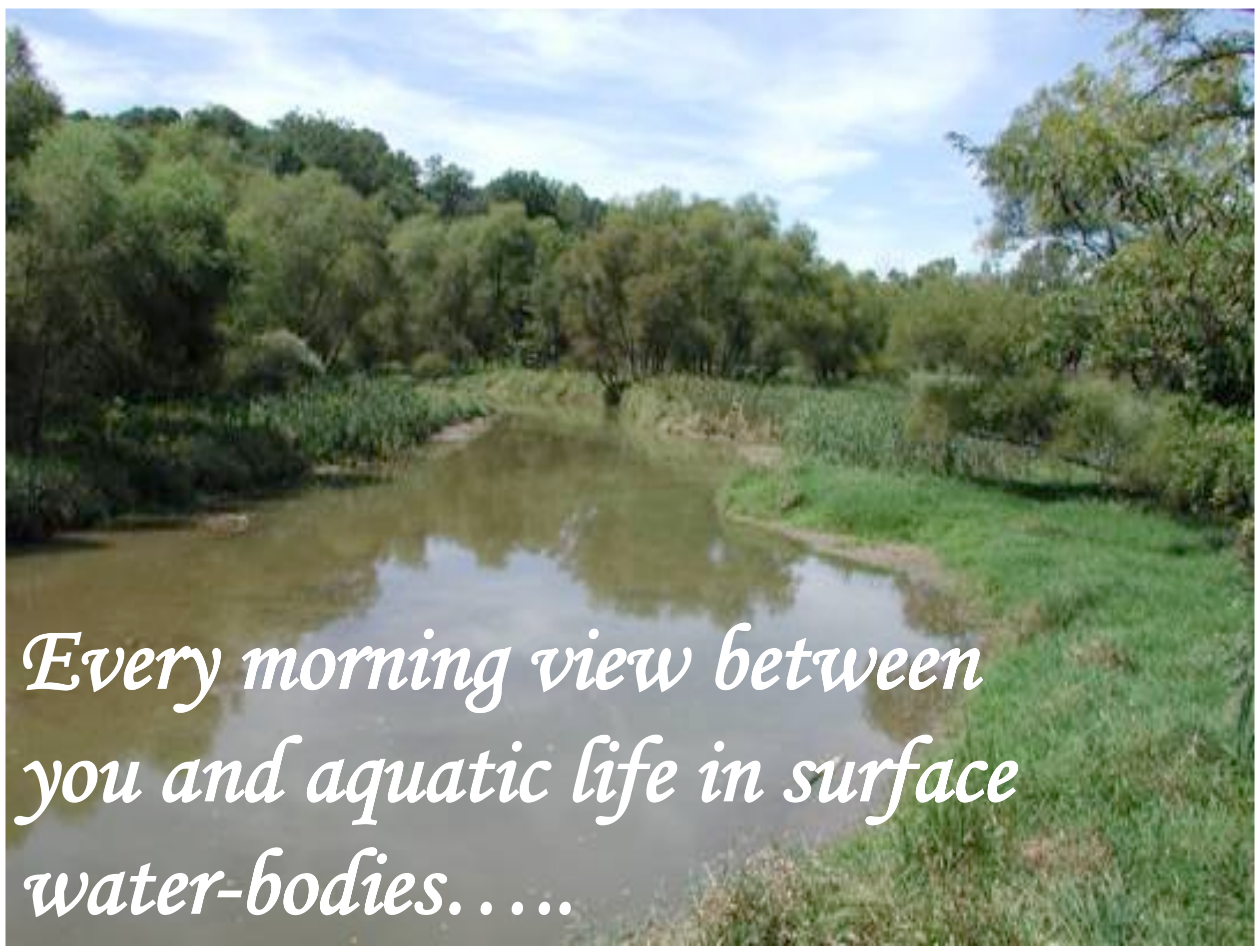




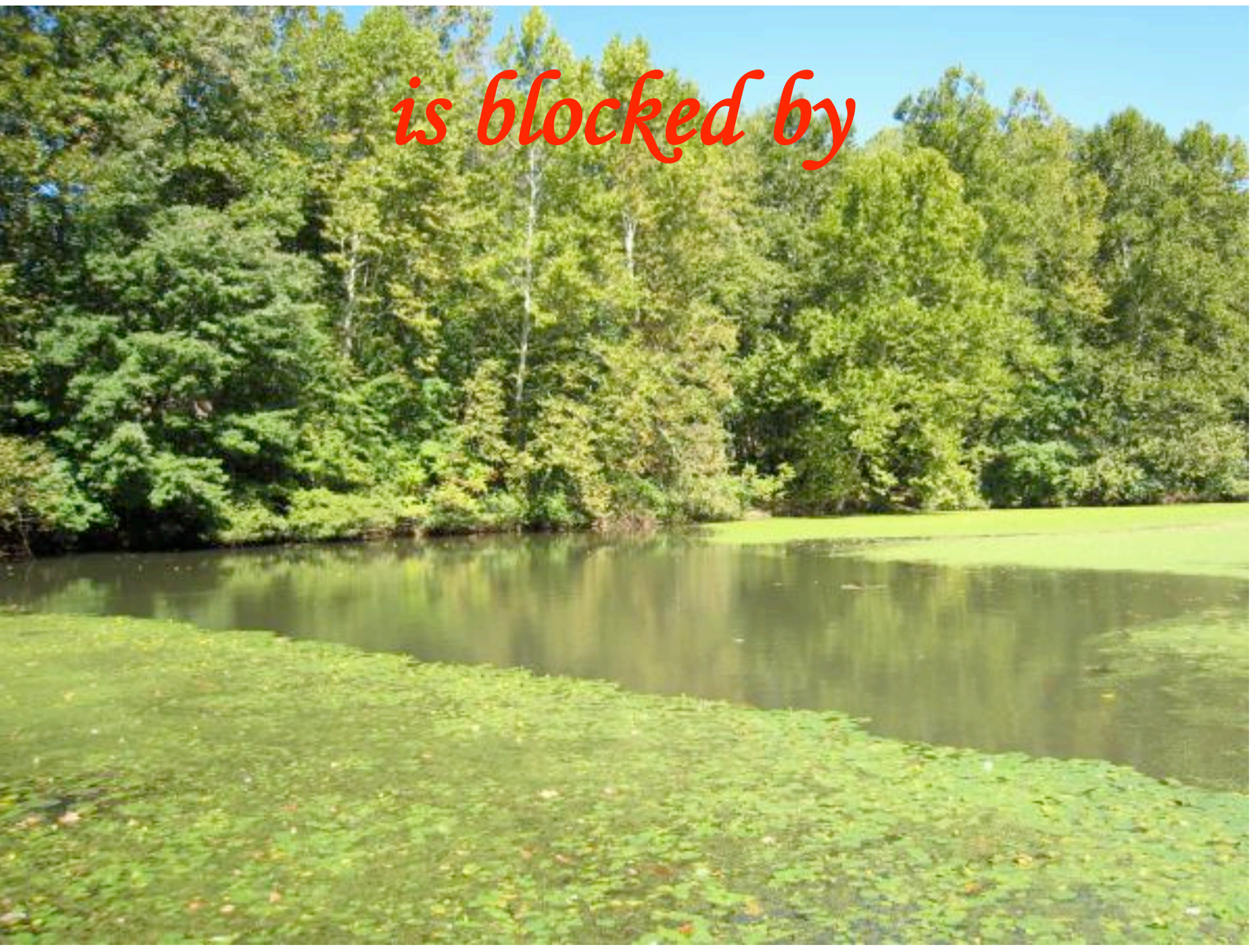




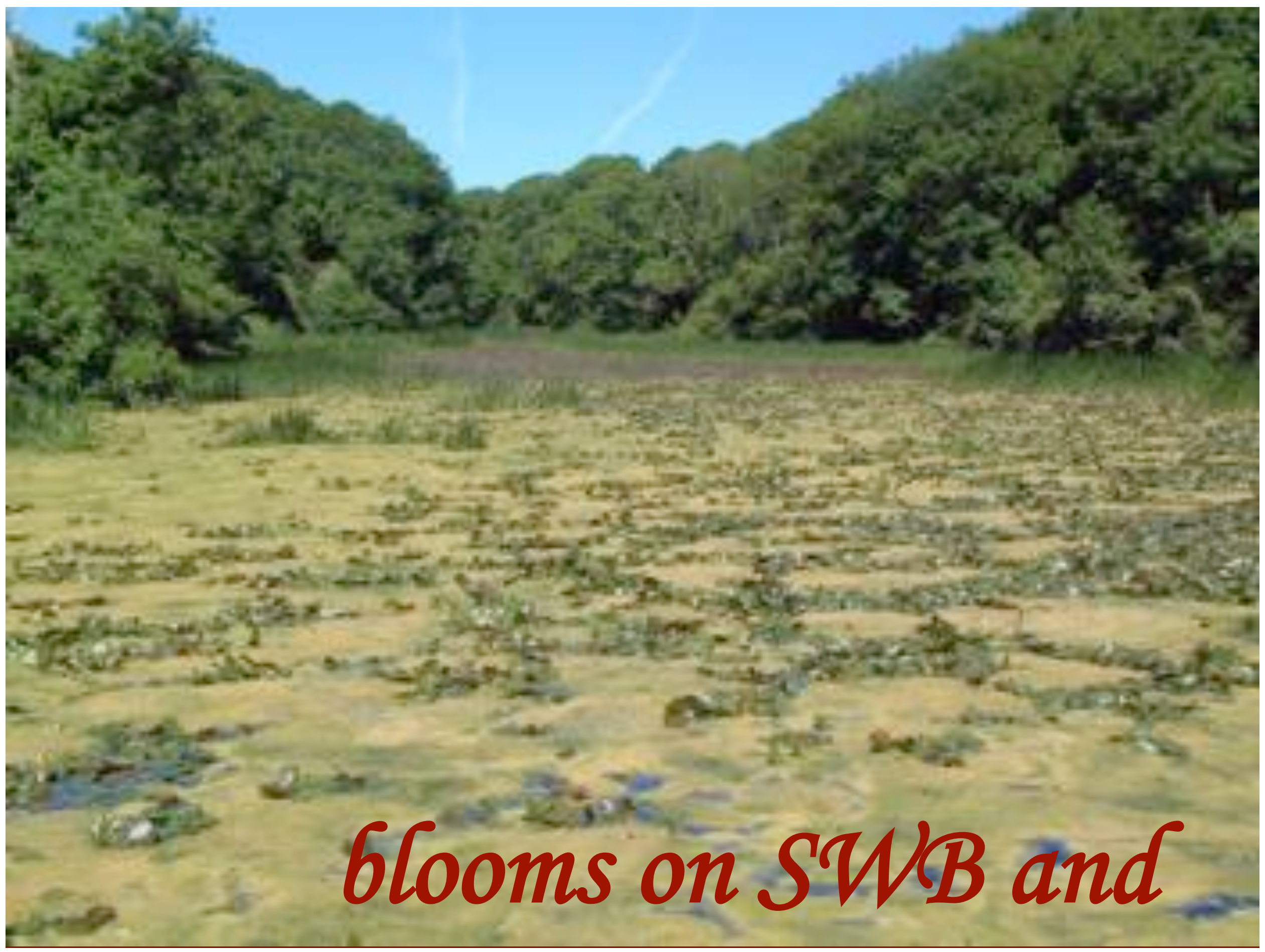




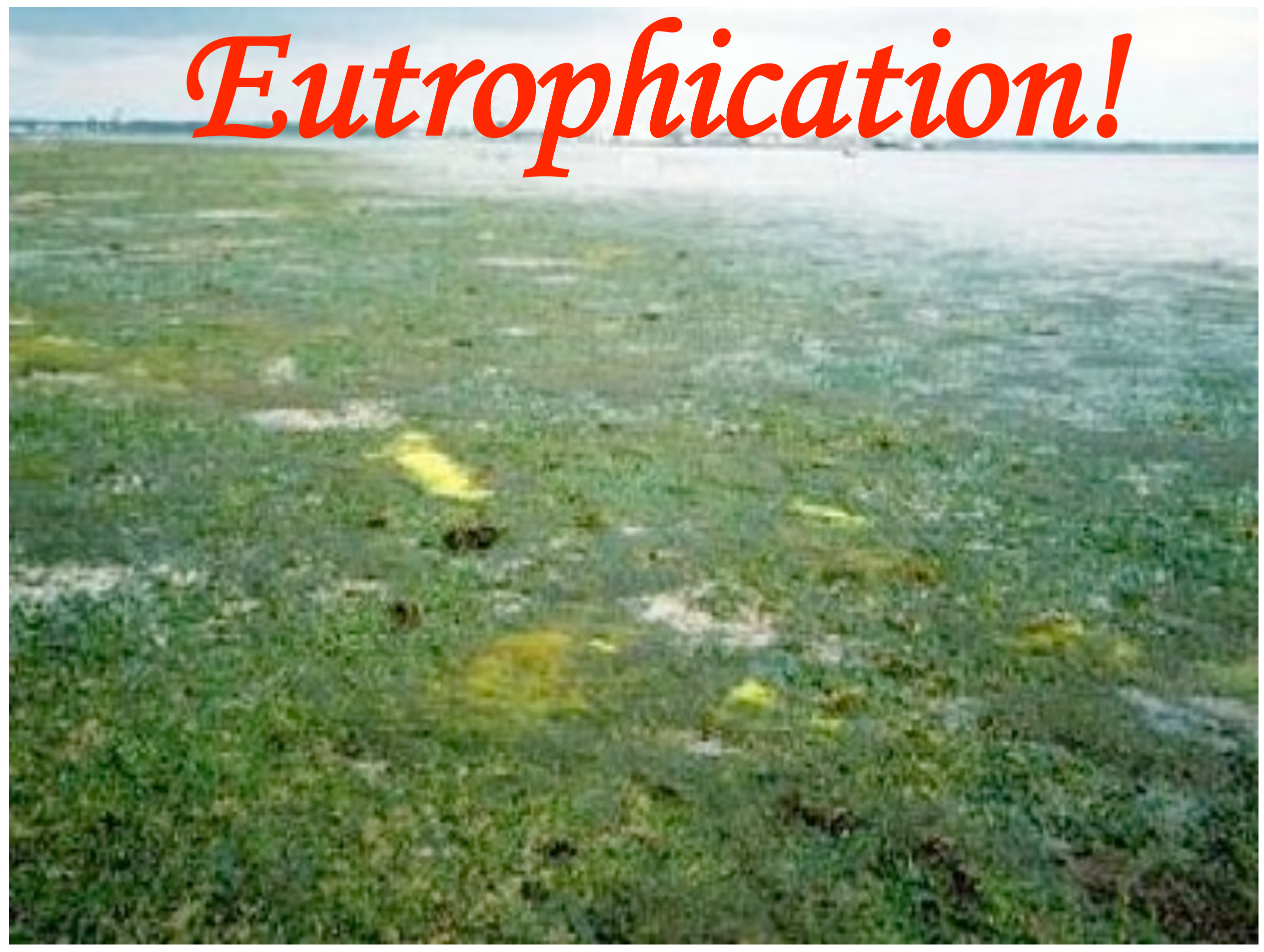




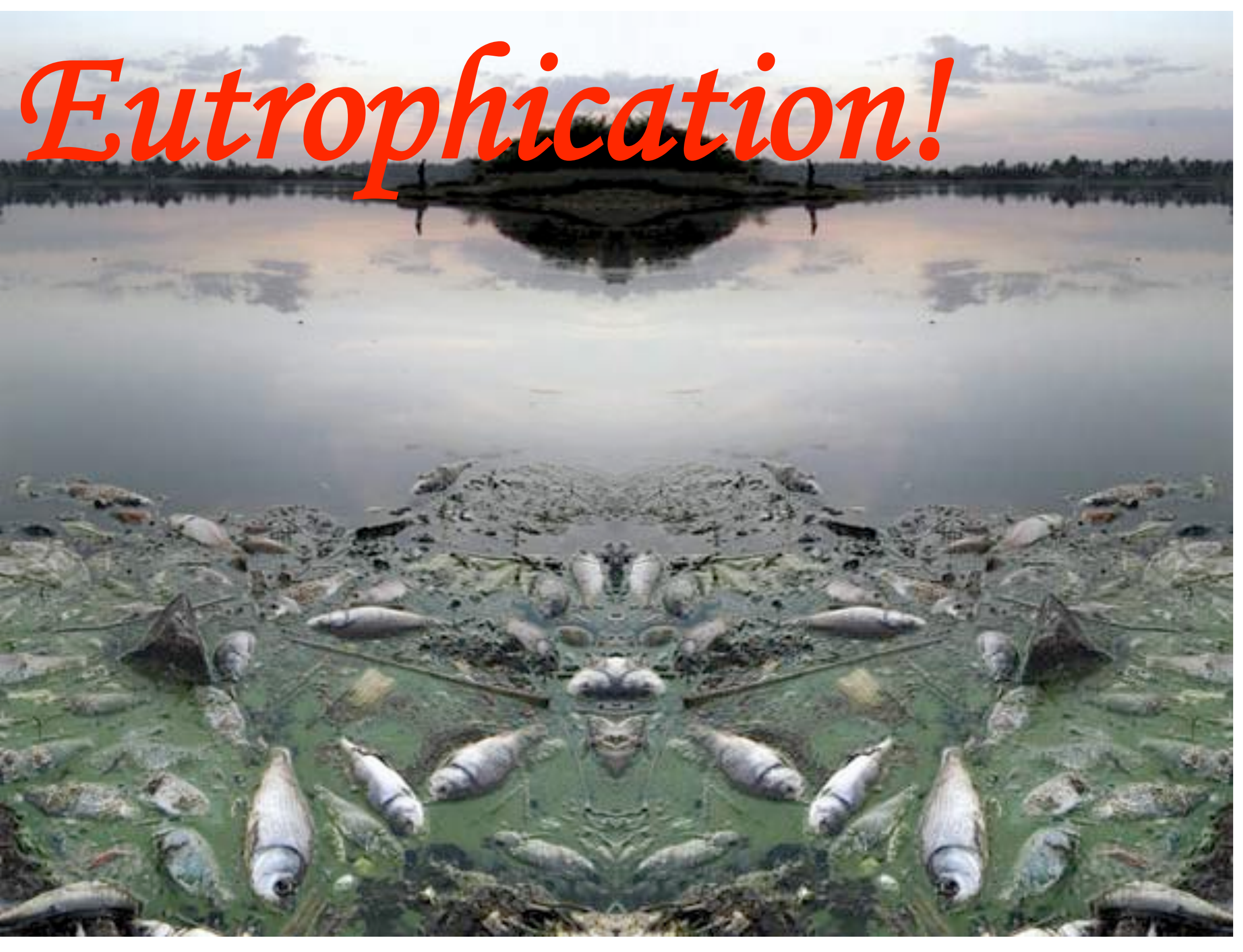




\section{Eutrophication!}




\section{Eutrophication}

A threat to quality of surface and ground water bodies (SWB) and to bio-

diversity of the aquatic eco-system

It snaps dynamics of "human $\leftrightarrow$

landscape $\leftrightarrow$ aquatic" life support system 


\section{Why target P?}

- Phosphorus has a very low solubility in soils,

- Range of $\mathrm{P}$ availability is $<10^{-8} \mathrm{M}$ in some very poor tropical soils,

- In the order of $10^{-6} \mathrm{M}$ in temperate soils,

$-10^{-5} \mathrm{M}$ in many soils of moderate $\mathrm{P}$ status,

And it can exceed $10^{-4} \mathrm{M}$ in some well supplied soils. 
$\square$ To maintain the desired level of P in soil solution; a key to productivity, excess amounts of $\mathrm{P}$ is added to soils, and the phenomenon continues for years.

$\square$ The annual surface runoffs is estimated between 0.01 and $3.00 \mathrm{~kg} \mathrm{P/ha} \mathrm{and}$ annual erosion of P-containing soil minerals is between 0.1 and $10 \mathrm{~kg} / \mathrm{ha}$ (Brady and Weil, 2002). 
- Thus phosphorous is leached with the surface run-offs and finally form sediments in the water bodies.

- As these sediments become anoxius, increments of transformation from solid to solution phase rises because of anaerobic conditions that facilitates reduction of $\mathrm{Fe}^{3+}$ and $\mathrm{Mn}^{4+}$ to $\mathrm{Fe}^{2+}$ and $\mathrm{Mn}^{2+}$ respectively. 


\section{Phosphorus turnover after 25 years of fertilizer experiment in a groundnut-wheat-sorghum cropping system at Junagarh (Gujarat).}

\begin{tabular}{|c|c|c|c|c|}
\hline Treatment & $\begin{array}{c}\text { Initial } \\
\text { P } \\
\text { statu } \\
\text { S }\end{array}$ & $\begin{array}{c}\text { Nutrient } \\
\text { additi } \\
\text { on }\end{array}$ & $\begin{array}{l}\text { Nutrient } \\
\text { remo } \\
\text { val }\end{array}$ & $\begin{array}{l}\text { End of the } \\
\text { exper } 1 \\
\text { ment P } \\
\text { status }\end{array}$ \\
\hline \multicolumn{5}{|c|}{------------------- $\mathrm{kg} \mathrm{ha-1}$} \\
\hline $\begin{array}{l}\mathrm{F}_{1} \text { Control } \\
\mathrm{F}_{2} \mathrm{FYM} \\
\mathrm{F}_{3} \mathrm{NP} \\
\mathrm{F}_{4} \mathrm{NPK}\end{array}$ & $\begin{array}{l}27.5 \\
27.5 \\
27.5 \\
27.5\end{array}$ & $\begin{array}{l}0 \\
546 \\
1490 \\
1566\end{array}$ & $\begin{array}{l}204 \\
599 \\
591 \\
778\end{array}$ & $\begin{array}{l}19.4 \\
23.5 \\
25.3 \\
25.7\end{array}$ \\
\hline
\end{tabular}




\section{How can we increase productivity?}

- It could be discerned from these experiments and also many other similar experiments conducted world over that small amounts of addition of phosphorus can remove excess $\mathrm{P}$ from soils provided solution $P$ is maintained in such a manner that productivity is sustained. 


\section{Causes of $\mathrm{P}$ accumulation}

-Excess application as a fertilizer

- Phosphorus buffering 
- The phenomenon; phosphorus buffering is a major contributor to eutrophication and remains a major problem years after the release of $\mathrm{P}$ is brought under control.

- Critical levels in water that can trigger algae growth have been reported to be as little as 20 parts per billion (ppb) 


\section{Promises of nanotechnology}

- Nanoscience and its applied sphere that is known as nanotechnology have potential to bring the next revolutionary breakthrough in agriculture-biased natural resource management.

-SEM, TEM, and AFM, and their attachments e.g., EDS are used for soil study. 


\section{-Electron waves in SEM and TEM and laser beam in AFM are used for coalescing micrographs.}

The advantages with EM are high resolution imaging, high magnification, and great depth of focus 


\section{Miracles of nano-P}

$\square$ Addition of small amount of addition of $P$ can remove excess $P$.

- Nano-P could possibly play a role in it

$\checkmark P$ must be applied to soils in amount exact to the requirement of crop

- Nanoscience approach can deal with the twin contradictions - between low solubility and excess application 


\section{Miracles of nano-P}

- Improve nutrient use efficiency

- Reduce P build ups in soils

- Reducing its load in SWB

-Checking contamination in drinking water

- Nano-technology has opened up new opportunities to improve nutrient use efficiency and minimize costs of environmental protection. 
Nanoscience and nanotechnology have found applications for the production of food and protection of environmental quality by:

1. Improving efficiency of native and applied phosphorus in soils,

2. Regulation of essential and toxic elements, associated with phosphorous in pedosphere-hydrosphere continuum,

3. Ion transport in soil-plant system, especially in the rhizosphere,

4. Increased endeavor towards precision farming w.r.t. phosphorous. 


\section{What will nano materials do to the environment?}

- Our expanding ability to synthesize nanoparticles for use in electronics, biomedical, ceramics, pharmaceutical, cosmetic, energy, environmental, catalytic, material etc. has alarmed concern for these particles role in environmental safety.

\begin{tabular}{|c|c|}
\hline Year & $\begin{array}{c}\text { Amount of } \\
\text { Engineered } \\
\text { material } \\
\text { used }\end{array}$ \\
\hline 2004 & 2000 tons \\
\hline $2011-2020$ & $\begin{array}{c}58000 \text { tons } \\
\text { (expected) }\end{array}$ \\
\hline
\end{tabular}




\section{Zeophonics}

- System founded on the concept of interconnected nature of all life-forms and life-support-forms

$\square$ Relies on recycling and operation of system-components

The system provides a framework where impetus and response are almost equal. 
$\square$ This is the only means of survival in the extraterrestrial planets, space stations, and in the Antarctica

To comprehend P dynamics, land and SWB system must be treated holistically, and sub-divided into components, each with realistic independent systemvariables coupled with the processes, which tie these system variables. 
- In nano-P ventures high resolution imaging not only provides evidence of the changes that occur in various phases, but also an indispensable tool to understand how dynamic systems operate. 


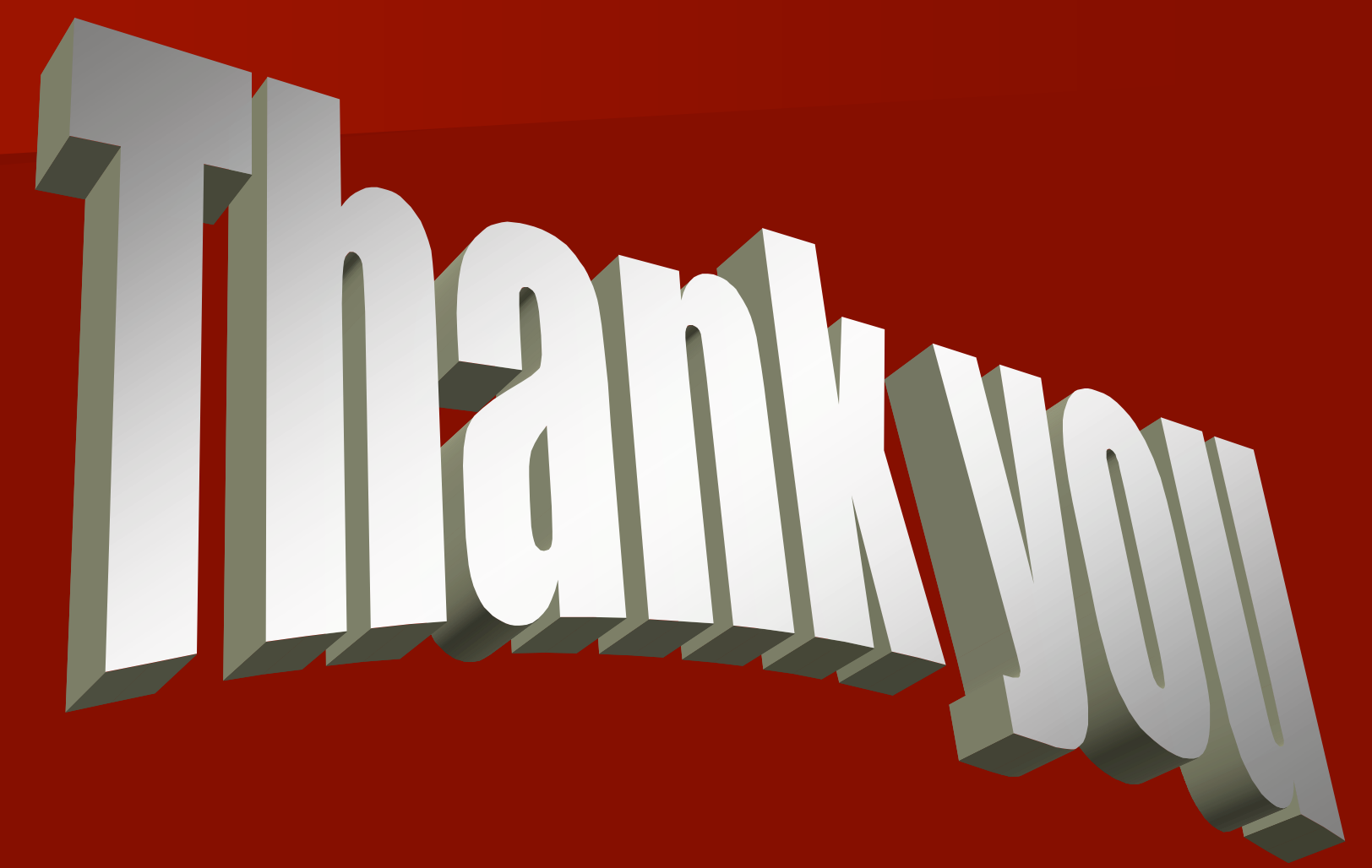

